\title{
Knowledge and attitude towards the practice of temporary contraceptive methods among pregnant women attending a teaching hospital in Puducherry
}

\section{Ananthi Kasinathan, Himabindu Nagulapally*}

Department of Obstetrics and Gynecology, Indira Gandhi Medical College and Research Institute, Kadirkamam, Puducherry, India

Received: 29 September 2020

Revised: 22 October 2020

Accepted: 23 October 2020

\section{*Correspondence:}

Dr. Himabindu Nagulapally, E-mail: hbindu27@yahoo.co.in

Copyright: (C) the author(s), publisher and licensee Medip Academy. This is an open-access article distributed under the terms of the Creative Commons Attribution Non-Commercial License, which permits unrestricted non-commercial use, distribution, and reproduction in any medium, provided the original work is properly cited.

\section{ABSTRACT}

Background: Knowledge and access to contraception is the basic right of every woman. This is one of the goals of National family planning programme. This study gauges the knowledge of antenatal women about temporary contraceptive methods available in our outpatient department and their attitude towards its practice.

Methods: This is a descriptive cross-sectional study carried out at Indira Gandhi medical college and research institute, Puducherry, between March 2019 to May 2019. 270 pregnant women were chosen and with their consent, using a predesigned questionnaire, their awareness regarding contraception was assessed. Then each participant was counselled regarding the various methods and their attitude towards choosing a temporary contraceptive method was assessed using a questionnaire. The data was entered in SPSS software and analyzed.

Results: In this study, $88.8 \%$ belonged to $20-30$ years, $77 \%$ had received school education and $80.3 \%$ were home makers. $72.9 \%$ were primigravidas. $55.8 \%$ of primis and $95.8 \%$ of multis knew about spacing. In primis, $67.5 \%$ knew about IUCDs. In multis, $95.8 \%$ knew about condoms. Knowledge of depo provera was poor. The most preferred contraceptive was condom followed by $\mathrm{CuT}$ and pills.

Conclusions: This study shows that it is important to create awareness about temporary contraceptive methods and its free availability in the hospitals. Further pregnant women need to be given more information about oral pills, emergency and injectable contraceptive methods. The Government has to work in unison with hospitals and its staff along with the media to achieve this goal.

Keywords: Knowledge, Attitude, Contraception, Pregnant women

\section{INTRODUCTION}

India is the first country in the world to initiate the family planning program in $1952 .{ }^{1}$ Its aim was to lower fertility, slow population growth rate, promote reproductive health and reduce maternal, infant and child mortality and morbidity. Highly effective contraceptive methods have been available since 1960 s. $^{2}$
A woman's ability to time her pregnancy, space and limit the number of pregnancies has direct impact on her health and wellbeing as well as on the outcome of her pregnancy. Unintended pregnancies and unsafe abortions can be prevented besides protecting themselves from sexually transmitted diseases by adopting appropriate contraceptives. Maternal deaths due to these causes can thus be prevented. ${ }^{3}$ 
Even though $90 \%$ of population are aware of family planning methods, hardly $50 \%$ of them practice it. ${ }^{4}$ There exists a fear about its safety and also doubts about its side effects. In addition, they lack information about the recent methods available and from where to procure them.

In current study, authors have assessed the level of awareness among the antenatal women about the temporary methods of contraception available in outpatient department and measured their attitude towards adopting them.

Objective of current study was to help patients comprehend and in the process, promote acceptance about the various temporary family planning methods and help to clear any misconceptions about the same.

\section{METHODS}

Current study is a descriptive cross-sectional study conducted in the outpatient department of obstetrics and gynecology at Indira Gandhi medical college and research institute, Kadirkamam, Puducherry, India between March 2019 to May 2019. 270 women attending antenatal clinic for routine check up were selected by simple random sampling.

Both primi and multigravida between the age group 1835 years, who could speak and write Tamil and/or English and were willing to participate, were included. Pregnant women above 35 years and women who were not conversant in Tamil or English and those who did not wish to participate were excluded. The purpose of the study was explained to them and consent was obtained.

Using a predesigned questionnaire, awareness regarding contraception and temporary contraceptives was assessed. Following this each participant was counselled regarding the various methods of contraception by a health care worker and their attitude towards choosing a temporary contraceptive method was also noted using the questionnaire. The data collected was entered in SPSS and analysed using descriptive statistics.

\section{RESULTS}

Out of the total 270 pregnant women, majority (88.8\%) were in the age group of 20-30 years. Nearly three-fourth of them $(77.0 \%)$ were school educated and $80.3 \%$ were home makers. $197(72.9 \%)$ were primi gravida and Hindus comprised $89.6 \%$ (Table 1).

Among the primigravidas, about 55\% knew that spacing was essential, that contraceptives were useful to this end and that they were available free of cost. $37.5 \%$ of them were aware that contraception was needed in postpartum period but $92.3 \%$ asked for more information regarding contraception. Knowledge among multigravidas was reasonably good as is evident in (Table 2). But only
$58.9 \%$ felt the need for contraception in postpartum period (Table 2).

Out of the 197 primigravidas, 67.5\% knew about IUCD and $51.7 \%$ knew of its availability in our OPD. Awareness of depo provera was poor (2.5\%). Multi gravidas had good knowledge about nearly all the temporary methods and most of them knew about the availability of pills and IUCD. Health care workers had been the source of information for both groups of women (Table 3).

Table 1: Socio-demographic data of participants $(n=270)$.

\begin{tabular}{|llll|}
\hline Characteristics & Category & $\mathbf{N}$ & $\%$ \\
\hline \multirow{3}{*}{ Age (years) } & $<20$ & 12 & 4.4 \\
\cline { 2 - 4 } & $20-30$ & 240 & 88.8 \\
\cline { 2 - 4 } & $>30$ & 18 & 6.6 \\
\hline \multirow{3}{*}{$\begin{array}{l}\text { Education } \\
\text { qualification }\end{array}$} & $\begin{array}{l}\text { Slliterate } \\
\text { educated }\end{array}$ & 208 & 1.4 \\
\cline { 2 - 4 } & Graduate & 58 & 21.4 \\
\hline \multirow{2}{*}{ Occupation } & Office workers & 53 & 19.6 \\
\cline { 2 - 4 } & Home makers & 217 & 80.3 \\
\hline \multirow{3}{*}{ Religion } & Hindu & 242 & 89.6 \\
\cline { 2 - 4 } & Christian & 18 & 6.6 \\
\cline { 2 - 4 } Parity & Muslim & 10 & 3.7 \\
\cline { 2 - 4 } & Primi & 197 & 72.9 \\
\cline { 2 - 4 } & Multi & 73 & 27.0 \\
\hline
\end{tabular}

Table 2: Awareness about contraception among participants.

\begin{tabular}{|c|c|c|c|c|}
\hline \multirow{3}{*}{ Knowledge } & \multicolumn{2}{|l|}{ Agree } & \multicolumn{2}{|c|}{ Disagree } \\
\hline & $\begin{array}{l}\text { Primi, } \\
\text { N=197 }\end{array}$ & $\begin{array}{l}\text { Multi } \\
\text { N=73 }\end{array}$ & $\begin{array}{l}\text { Primi } \\
\text { N=197 }\end{array}$ & $\begin{array}{l}\text { Multi } \\
N=73\end{array}$ \\
\hline & $\mathbf{N}(\%)$ & $\mathbf{N}(\%)$ & $\mathbf{N}(\%)$ & $\mathbf{N}(\%)$ \\
\hline $\begin{array}{l}\text { Spacing is } \\
\text { essential }\end{array}$ & $\begin{array}{l}110 \\
(55.8)\end{array}$ & $\begin{array}{l}70 \\
(95.8)\end{array}$ & $\begin{array}{l}87 \\
(44.1)\end{array}$ & $\begin{array}{l}3 \\
(9.5)\end{array}$ \\
\hline $\begin{array}{l}\text { Contraceptives } \\
\text { help in spacing }\end{array}$ & $\begin{array}{l}109 \\
(55.3)\end{array}$ & $\begin{array}{l}61 \\
(83.5)\end{array}$ & $\begin{array}{l}88 \\
(44.6)\end{array}$ & $\begin{array}{l}12 \\
(16.4)\end{array}$ \\
\hline $\begin{array}{l}\text { Contraceptives } \\
\text { are available } \\
\text { free of cost }\end{array}$ & $\begin{array}{l}109 \\
(55.3)\end{array}$ & $\begin{array}{l}59 \\
(80.8)\end{array}$ & $\begin{array}{l}88 \\
(44.6)\end{array}$ & $\begin{array}{l}14 \\
(19.1)\end{array}$ \\
\hline $\begin{array}{l}\text { Contraception } \\
\text { is needed in } \\
\text { post partum } \\
\text { period }\end{array}$ & $\begin{array}{l}74 \\
(37.5)\end{array}$ & $\begin{array}{l}43 \\
(58.9)\end{array}$ & $\begin{array}{l}123 \\
(62.4)\end{array}$ & $\begin{array}{l}30 \\
(41.0)\end{array}$ \\
\hline $\begin{array}{l}\text { Need more } \\
\text { information } \\
\text { regarding } \\
\text { contraception }\end{array}$ & $\begin{array}{l}182 \\
(92.3)\end{array}$ & $\begin{array}{l}13 \\
(17.8)\end{array}$ & $\begin{array}{l}15 \\
(7.6)\end{array}$ & $\begin{array}{l}60 \\
(82.1)\end{array}$ \\
\hline
\end{tabular}

Out of the various contraceptive methods, condoms were most preferred followed by $\mathrm{CuT}$ and pills, because it is easy to use and it is easily available. Fear about the possible side effects deterred them from adopting certain methods of contraception (Table 4-6). 
Table 3: Awareness about contraceptives.

\begin{tabular}{|c|c|c|c|c|}
\hline \multirow{2}{*}{$\begin{array}{l}\text { Variables } \\
\text { Methods* }\end{array}$} & \multicolumn{2}{|c|}{$\begin{array}{l}\text { Primi } \\
(n=197)\end{array}$} & \multicolumn{2}{|c|}{$\begin{array}{l}\text { Multi } \\
(n=73)\end{array}$} \\
\hline & $\mathbf{N}$ & $\%$ & $\mathbf{N}$ & $\%$ \\
\hline Pills & 87 & 44.1 & 58 & 79.4 \\
\hline IUCD & 133 & 67.5 & 62 & 84.9 \\
\hline Condom & 52 & 26.3 & 70 & 95.8 \\
\hline $\begin{array}{l}\text { Injection depo- } \\
\text { provera }\end{array}$ & 5 & 2.5 & 28 & 38.3 \\
\hline \multicolumn{5}{|c|}{ Availability in outpatient department* } \\
\hline Mala N & 50 & 25.3 & 56 & 76.7 \\
\hline Centchroman & 8 & 4.0 & 12 & 16.4 \\
\hline $\begin{array}{l}\text { Injection depo- } \\
\text { provera }\end{array}$ & 5 & 2.5 & 11 & 15.0 \\
\hline $\mathrm{CuT}$ & 102 & 51.7 & 62 & 84.9 \\
\hline Male condom & 3 & 1.5 & 28 & 38.3 \\
\hline \multicolumn{5}{|c|}{ Source of information* } \\
\hline Doctor & 12 & 6.0 & 53 & 72.6 \\
\hline Nurse & 27 & 13.7 & 60 & 82.1 \\
\hline Relatives/friends & 16 & 8.1 & 35 & 47.9 \\
\hline Media & 14 & 7.1 & 23 & 31.5 \\
\hline
\end{tabular}

Table 4: Preference of contraceptives.

\begin{tabular}{|lll|}
\hline \multirow{2}{*}{ Methods } & $\begin{array}{l}\text { Primi } \\
(\mathbf{n = 1 9 7 )}\end{array}$ & $\begin{array}{l}\text { Multi } \\
(\mathbf{n = 7 3 )}\end{array}$ \\
\hline N (\%) & $\mathbf{N}(\mathbf{\%})$ \\
\hline Mala (N) & $24(12.2)$ & $16(21.9)$ \\
\hline Cu T & $33(16.7)$ & $35(47.9)$ \\
\hline Centchroman & $19(9.6)$ & $11(15.0)$ \\
\hline Emergency pill & $9(4.5)$ & $19(26.0)$ \\
\hline Injection depo provera & $8(4.0)$ & $17(23.2)$ \\
\hline Male condom & $102(51.7)$ & $52(71.2)$ \\
\hline
\end{tabular}

Table 5: Reason for accepting a contraceptive method $(n=270)$.

\begin{tabular}{|lll|}
\hline Reason & N & $\%$ \\
\hline Ease of availability & 260 & 96.2 \\
\hline Easy to use & 233 & 86.2 \\
\hline Less/no side-effects & 131 & 48.5 \\
\hline $\begin{array}{l}\text { Fertility reversed immediately on } \\
\text { stopping }\end{array}$ & 182 & 67.4 \\
\hline
\end{tabular}

\section{DISCUSSION}

A report by Singh et al shows that half of the 48.1 million pregnancies in India were unintended and that 15.6 million (14.1-17.3 million) pregnancies ended in abortions. ${ }^{5}$ The study results point to the huge burden of unintended pregnancy in India. These findings show that improved policies to increase access to contraceptive services is an urgent priority in India to help millions of women avoid unintended pregnancies. National health systems resource data of 2015 for Puducherry shows an abortion rate of $7.9 \%$ as against the expectant pregnancies and a $41 \%$ unmet need for temporary contraception. ${ }^{6}$ The national statistics for the same year reported the unmet need for contraception as $12 \% .^{7}$ These findings indicate the urgent need to improve the awareness and access to contraceptive methods in India, especially in the union territory of Puducherry. Pregnancy is an ideal time to educate and motivate women about adopting family planning methods following delivery. Hence this cross-sectional study was undertaken in the Government medical college and research institute of Puducherry to assess the knowledge, attitude and preference of temporary contraceptive methods among pregnant women attending the outpatient department.

Table 6: Reason for refusing a contraceptive method $(n=270)$.

\begin{tabular}{|lll|}
\hline Reason & N & $\%$ \\
\hline Fear of side effects & 242 & 89.6 \\
\hline Religious beliefs & 48 & 17.7 \\
\hline Don't desire immediate contraception & 213 & 78.8 \\
\hline Partner's denial & 172 & 63.7 \\
\hline Family's refusal & 187 & 69.2 \\
\hline Fear of it affecting sexual life & 162 & 60 \\
\hline
\end{tabular}

Out of the 270 participants recruited in the study majority were in the age group of $20-30$ years $(88.8 \%)$. In other studies done on the knowledge, attitude and practice of contraception majority of the participants were in the same age group. ${ }^{8,9}$ An extensive review of literature did not reveal many studies done among pregnant women in India. Most of the studies have been done among non pregnant women in reproductive age group. Most of the participants received high school education (77\%) and were home makers $(80.3 \%)$. Majority of them belonged to the Hindu religious belief. Out of the participants $73 \%$ were primigravidas and $27 \%$ were multigravidas.

Only $66.7 \%$ of the participants were aware that spacing was essential and $62.2 \%$ were aware about the availability of spacing methods. This was found to be lower than the awareness rate found in other Indian studies of $91 \%, 82.8 \%$ and $100 \% .^{2,9,10}$ Out of the primigravidae $44.6 \%$ and of the multigravidae $19.1 \%$ were not aware that contraceptives are available free of cost in the Government hospitals and health centres. As expected, the awareness was found to be significantly greater among multigravidae when compared to primigravidae. $62.4 \%$ of the primigravidae and $41 \%$ of the multigravidae were not aware of the need of contraception in the immediate postpartum period. This correlates with the various reports of unintended pregnancies among lactating mothers ranging from 14.3 to $32.8 \% .^{11,12}$ Majority of the primigravidae felt that there was a need for more information regarding contraception. This shows a greater need of education about contraception in the women of Puducherry, especially the primigravidae. 
Out of the various contraceptive methods available majority of the participants were aware of intrauterine contraceptives devices (67.5\% primi and $84.9 \%$ multi). Next to IUCD's the awareness was more with respect to Oral contraceptive pills (44.1\% primi and $79.4 \%$ multi). Most of the multigravidae were aware about condoms, but the awareness regarding condoms was very low among the primigravidae (only 26.3\%). The awareness regarding injectable contraceptives was very low $(2.5 \%$ primi, $38.3 \%$ multi). Most of the other studies showed a greater awareness regarding oral contraceptive pills when compared to Intrauterine devices. ${ }^{8,9,13} \mathrm{~A}$ study done in Coimbatore on pregnant mothers found an $83 \%$ awareness of oral contraceptive pills and only $10 \%$ awareness of IUCD. ${ }^{14}$ All the studies done so far reveal a very low knowledge regarding Injectable contraceptives. The results of our study are consistent with the data regarding the contraceptive use in Puducherry published in the National health systems resource data of 2015 (Figure 1). The higher awareness regarding IUCD could be due to the greater counselling regarding post placental and post partum IUCD insertion during antenatal checkups in hospitals and primary health centres in Puducherry. This suggests the greater need of information to couple in reproductive age regarding pills, condoms and injectable contraception.

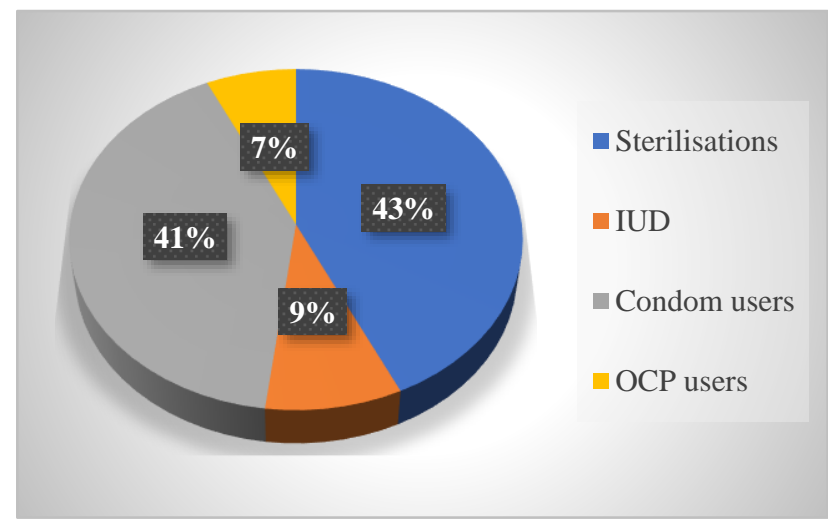

Figure 1: Pondicherry; distribution of family planning methods against total reported.

The analysis of the awareness of the participants regarding the availability of the various contraceptive methods in our hospital showed a correlation between the awareness of the methods seen above. Majority were aware of the availability of IUCD $(51.7 \%$ primi and $84.9 \%$ multi) followed by oral pills and condoms. These findings were also consistent with data on the source of information regarding contraception. Most of the participants obtained information from doctors and nurses. Only $31.5 \%$ of multigravidae and $7.1 \%$ of primigravide obtained information from the media. These findings suggest the hospital and primary health centres to be the sources of information. These findings are consistent with other studies which show the hospitals to be the primary source of information regarding contraception. ${ }^{15}$ Interestingly a study done in Sikkim showed that media was the primary source of information regarding contraception for adolesecnts and college students ( $73 \%$ media, $33 \%$ newspaper). Only $21 \%$ of the college students obtained information from health care workers in their study. ${ }^{16}$ Our study shows a greater need to spread awareness regarding contraception by home visits of health care workers and media in Puducherry.

In the analysis of the preferred method of contraception by the participants following the counselling by a health care worker, majority of the participants preferred male condoms $(51.7 \%$ primi and $71.2 \%$ multi) followed by IUCD and oral contraceptive pills. The preference for male condom was significantly higher compared to the other methods. There was no awareness among the participants regarding emergency contraception and centchroman tablets. Few of the participants selected them as the preferred method of contraception following counselling by the health care worker. Another study also showed male condom to be the preferred method whereas all the other studies showed oral contraceptive pills to be the preferred method..$^{9,13,14}$ These findings suggest a positive effect of counselling on acceptance of contraceptive methods and a greater need to spread awareness by media and repeated counselling on an individual basis. The three main reasons for accepting a particular method of contraception were found to be the ease of availability, ease of use and fewer side effects. These aspects we given more weightage than the failure rate of the method. This explains the preference among the participants for male condoms. The reasons for refusing a particular method of contraception were fear of side effects $(89.6 \%)$, spouse $(63.7 \%)$ or other family members $(69.2 \%)$ not accepting the use of contraception and the fear of sexual life being affected by it $(60 \%)$. Another important reason was the belief that contraception is not needed in the postpartum period during lactation (56.6\%). These finding suggest a very important role of spouse and family in choosing contraception. Evidence from the National family health survey 2015-16 shows strong intra household influence on contraceptive use among young women in India. The influence of the spouse and mother in law was found to be significantly higher in India compared to other countries. The use of contraception by another member in the household had a significantly positive effect on acceptance of contraception. ${ }^{17}$ All these findings show the importance of need of involving family in counselling regarding contraception. This again stresses the need for home visits by health care workers to counsel about contraception.

\section{Limitations}

Limitation of current study is that it assessed only the pregnant women. Inclusion of all women in the reproductive age group and comparing the pregnant and non-pregnant women would yield a more comprehensive picture to plan counselling programmes. 


\section{CONCLUSION}

To conclude, inspite of the female literacy rate in Puducherry being $80.67 \%$ (higher than national female literacy rate of $65.5 \%$ ), the unmet need for temporary contraception being $41 \%$ (much more than National unmet need of $12 \%$ ) raises a cause for immediate concern. ${ }^{18}$ This study being one of the very few studies in pregnant women demonstrates that visits to health care centres for antenatal care to be an opportune time for contraception counselling. There is a very urgent need to create awareness among the women of reproductive age group in Puducherry regarding contraception and availability of contraceptive methods free of cost in health care centres. A greater awareness is required with respect to oral pills, emergency and injectable contraceptive methods. This study also points to the need of greater involvement of media in creating awareness. The study shows a positive effect of counselling on the acceptance of contraception. Involving the spouse and the elder members of the household in choosing contraception by home visits of health care workers seems to be a wise approach. Thus a combined involvement of the government, hospitals, media and primary health care workers will go a long way in fulfilling the unmet needs of contraception in Puducherry.

\section{Funding: No funding sources}

Conflict of interest: None declared

Ethical approval: The study was approved by the Institutional Ethics Committee

\section{REFERENCES}

1. Park K. Text book of preventive and social medicine. 21st ed. Jabalpur: Banarsidas Bhanot; 2011:445.

2. Rao PD, Babu MS. Knowledge and use of contraception among Racha Koyas of Andhra Pradesh. Anthropol. 2005;7:115-19.

3. Weldegerima B, Denekew A. Women's knowledge, preferences, and practices of modern contraceptive methods in Woreta, Ethiopia. Res Social Adm Pharm. 2008;4:302-7.

4. District level household and facility survey. Available at: http://rchiips.org/ARCH-1.html. Accessed on 20 August 2020.

5. Singh S, Shekhar C, Acharya R, Moore AM, Stillman M, Pradhan MR, et al. The incidence of abortion and unintended pregnancy in India, 2015. Lancet Glob Health. 2018;6(1):e111-20.

6. National health systems resource data of 2015 , Puducherry. Available at: http://nhsrcindia.org/ resource-detail/pondicherry/MjA1. Accessed on 20 August 2020.

7. United Nations, the millennium development goals report 2015. Available at: https://www.un.org >MDG2015rev. Accessed on 20 August 2020.
8. Gayathry D, Ramana BV, Rao V. A study on assessment of knowledge towards family planning practices among the couples of reproductive age group in the field practice area of Prathima institute of medical sciences, Karimnagar. Int J Community Med Public Health. 2017;4(10):3740-7.

9. Shukla M, Fonseca M, Deshmukh P. A study on contraceptive knowledge, attitudes and practices among women in the reproductive age group. Int $\mathbf{J}$ Reprod Contracept Obstet Gynecol. 2017;6(8):35603.

10. Renjhen P, Gupta SD, Barua A, Jaju S, Khati B. A study of knowledge, attitude and practice of family planning among the women of reproductive age group in Sikkim. J Obstet Gynecol India. 2008;58: 63-7.

11. Ekpenyong CE, Daniel NE, Uwah AF, Ettebong EO, Ibu JO. Lactational amenorrhoea method of contraception: An in-depth study of awareness, knowledge and practice by breast feeding mothers with unintended pregnancies. Int J Med Med Sci. 2013;5(1):6-13.

12. Omar MS, Anna F. Pregnancy during breast feeding in rural Egypt. Contraception. 2008;77(5):350-4.

13. Kaushal SK, Saxena SC, Srivastava VK, Gupta SC, Nigam S. KAP study on Contraceptive methods in Kanpur district of U.P. Indian J Community Health.2010;22(1):33-8.

14. Nagamala J, Muthulakshmi P, Kayalvizhi M. A study to assess the knowledge, practice and attitude on temporary and permanent contraceptive methods among primi and multi mothers in selected areas in Coimbatore. Health Sci J. 2018;12(3):568.

15. Koranne PS, Wahane AR. An analysis of awareness and utilisation of contraceptives amongst married women attending a tertiary care hospital in Maharashtra, India. Natl J Community Med. 2014;5 (4):373-7.

16. Renjhen P, Kumar A, Pattanshetty S, Sagir A, Samarasinghe CM. A study on knowledge, attitude and practice of contraception among college students in Sikkim, India. J Turk Ger Gynecol Assoc. 2010;11 (2):78-81

17. Ranjana M, Mozumdar A, Acharya R, Mondal SK, Saggurti N. Intrahousehold influence on contraceptive use among married Indian women: Evidence from the National family health survey 2015-16. SSM Popul Health. 2020;11:2-8.

18. Population census 2011. Available at: https://www.census2011.co.in/. Accessed on 20 August 2020.

Cite this article as: Kasinathan A, Nagulapally $\mathrm{H}$. Knowledge and attitude towards the practice of temporary contraceptive methods among pregnant women attending a teaching hospital in Puducherry. Int J Reprod Contracept Obstet Gynecol 2020;9:4845-9. 